Provided for non-commercial research and education use. Not for reproduction, distribution or commercial use.

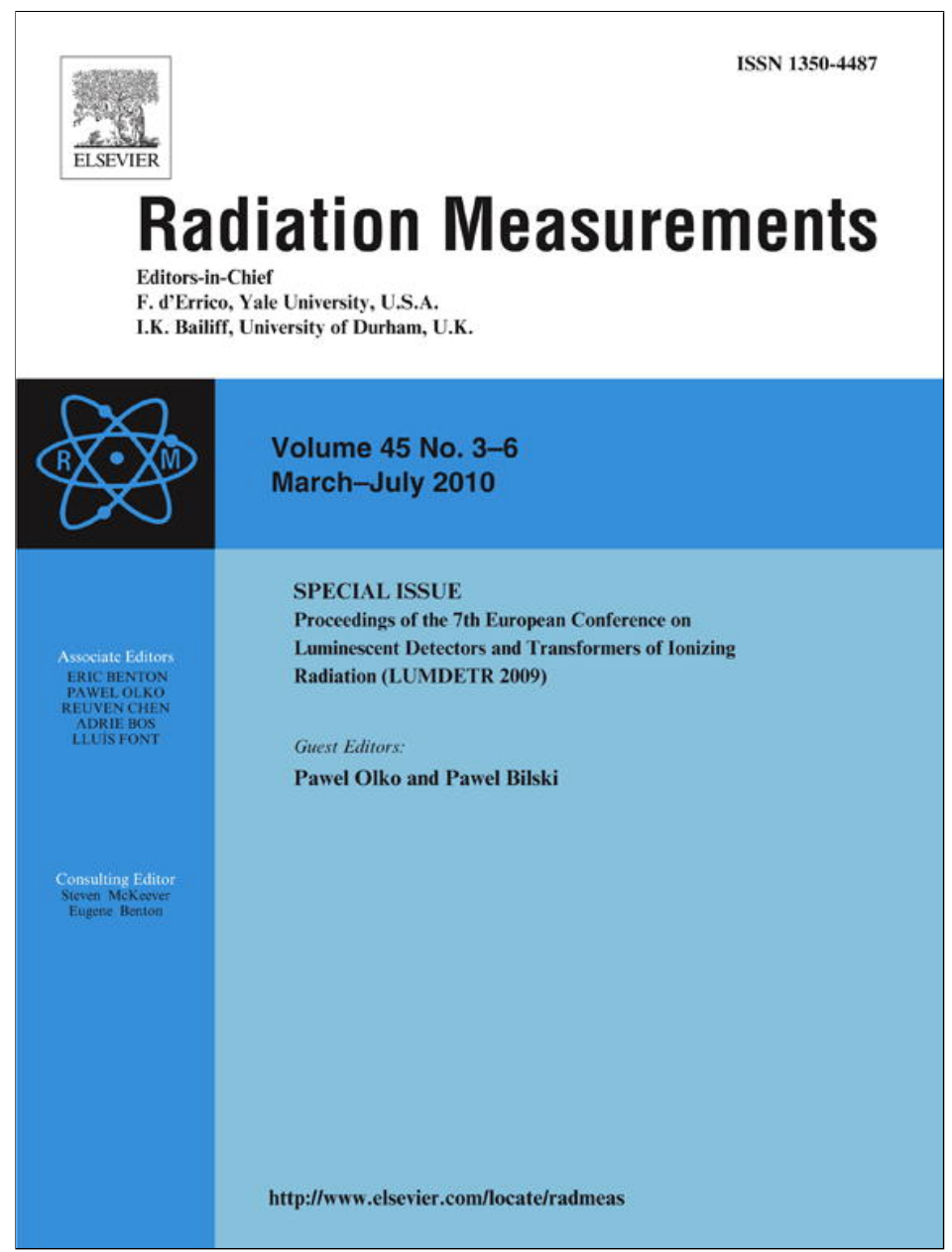

This article appeared in a journal published by Elsevier. The attached copy is furnished to the author for internal non-commercial research and education use, including for instruction at the authors institution and sharing with colleagues.

Other uses, including reproduction and distribution, or selling or licensing copies, or posting to personal, institutional or third party websites are prohibited.

In most cases authors are permitted to post their version of the article (e.g. in Word or Tex form) to their personal website or institutional repository. Authors requiring further information regarding Elsevier's archiving and manuscript policies are encouraged to visit:

http://www.elsevier.com/copyright 


\title{
VUV spectroscopy and electronic excitations in nano-size alumina
}

\author{
Marco Kirm ${ }^{\mathrm{a}, *}$, Eduard Feldbach ${ }^{\mathrm{a}}$, Aleksei Kotlov ${ }^{\mathrm{b}}$, Peeter Liblik ${ }^{\mathrm{a}}$, Aleksandr Lushchik ${ }^{\mathrm{a}}$, Marek Oja ${ }^{\mathrm{a}}$, \\ Eriks Palcevskis ${ }^{\mathrm{c}}$ \\ a Institute of Physics, University of Tartu, Riia 142, Tartu 51014, Estonia \\ ${ }^{\mathrm{b}}$ Hamburger Synchrotronstrahlungslabor HASYLAB at Deutsches Elektronensynchrotron DESY, Notkestraße 85, Hamburg 22607, Germany \\ ${ }^{c}$ Plasma E' Ceramic Technologies Ltd, Miera iela 34, Salaspils LV-2169, Latvia
}

\section{A R T I C L E I N F O}

\section{Article history:}

Received 17 August 2009

Received in revised form

22 November 2009

Accepted 6 December 2009

\section{Keywords:}

Transition alumina

Luminescence

Electronic excitations

Nano-particles

\begin{abstract}
A B S T R A C T
Luminescence properties and electronic excitations of $\delta$ - and $\Theta$-phases of $\mathrm{Al}_{2} \mathrm{O}_{3}$ nano-powders, prepared by plasma processing technique, were studied using time-resolved luminescence spectroscopy under vacuum ultraviolet excitation. The fundamental absorption edge was found at $7.5 \mathrm{eV}$, which is $1.5 \mathrm{eV}$ less than that of $\alpha-\mathrm{Al}_{2} \mathrm{O}_{3}$ in agreement with theoretical predictions for transition alumina. The broad-band emissions with maxima at 5.5 and $4.6 \mathrm{eV}$ are assigned to radiative decay of the intrinsic excitations. Emission of transition metal impurities was found near $1.75 \mathrm{eV}$. The emission bands peaked at 3.1 and $2.6 \mathrm{eV}$ are assigned to $\mathrm{F}^{+}$and $\mathrm{F}$ centres, respectively.
\end{abstract}

(c) 2009 Elsevier Ltd. All rights reserved.

\section{Introduction}

Alumina is widely used technological material in the form of ceramics or single crystals. The electronic properties of its stable $\alpha$-phase have been thoroughly investigated (Valbis and Itoh, 1991; Kirm et al., 1999). The metastable polymorphs $(\beta, \gamma, \delta, \Theta$, etc.) known as transition alumina have mainly found theoretical attention. Various physical properties of transition alumina have been evaluated theoretically (e.g. Lee et al., 2007; Ching et al., 2008). In $\alpha-\mathrm{Al}_{2} \mathrm{O}_{3}$ all $\mathrm{Al}$ ions have octahedral coordination $\left(\mathrm{AlO}_{6}\right)$, whereas in transition aluminas some of them are tetrahedrally coordinated $\left(\mathrm{AlO}_{4}\right)$. The number of occupied tetra- or octahedral sites varies for different polymorphs, which leads to remarkable differences in their properties. There are only a few experimental reports on intrinsic electronic properties obtained for $\delta-\mathrm{Al}_{2} \mathrm{O}_{3}$ powder (Kirm et al., 2005) or for mixed amorphous-crystalline $\mathrm{Al}_{2} \mathrm{O}_{3}$ films (Aarik et al., 2005). Luminescence properties of $\gamma$ - and $\delta-\mathrm{Al}_{2} \mathrm{O}_{3}$ nanopowders have been evaluated in Gorbunov et al. (2005) and nano-ceramics in Kortov et al. (2008). The main goal of our work was to investigate the electronic properties of the $\delta$ - and $\Theta$-phases of alumina and comparison of properties with the $\alpha$-phase. Also effects due to size of particles may influence optical properties of nano-powders.

\footnotetext{
* Corresponding author. Tel.: +372 7374601; fax: +372 7383033 .

E-mail addresses: marco@fi.tartu.ee, marco.kirm@ut.ee (M. Kirm).
}

\section{Experimental details}

The plasma processing technique (Palcevskis et al., 2001) was used to prepare nano-powders from the raw alumina of $99.7 \%$ purity. Various structural (XRD) and morphological characterization (AFM, TEM) methods were applied. The alumina powder was in the mixed $\delta$-, $\Theta-\mathrm{Al}_{2} \mathrm{O}_{3}$ crystallographic phase with spherical particle shape of 75 and $40 \mathrm{~nm}$ average size (specific surface area 20 and $50 \mathrm{~m}^{2} / \mathrm{g}$, respectively). Low temperature time-resolved VUV spectroscopy with synchrotron radiation (SR) was performed at the SUPERLUMI station (Zimmerer, 2007). Simultaneously with timeintegrated (TI) luminescence, spectra in two time windows with the length of $\Delta t$ and delayed by $\delta t$ relative to the exciting SR-pulse were registered. The cathodoluminescence $(\mathrm{CL})$ study was performed in Tartu. The CL spectra were corrected to the spectral transmission of the detection channel.

\section{Results and discussion}

As shown in Fig. 1a the electron beam excitation results in several overlapping emission bands with maxima at 5.5, 4.5, 3.3 and $2.2 \mathrm{eV}$. Selective excitation by $4.1 \mathrm{eV}$ photons reduces a number of bands and the main luminescence maximum is near $3 \mathrm{eV}$. In time-resolved spectra fast nanosecond and considerably slower microsecond components were found at 3.1 and $2.6 \mathrm{eV}$, respectively. Increase of exciting photon energy to $8.27 \mathrm{eV}$ adds luminescence bands in the UV region (Fig. 1b,c). There is always present an emission near $1.7 \mathrm{eV}$ with a long decay time. 


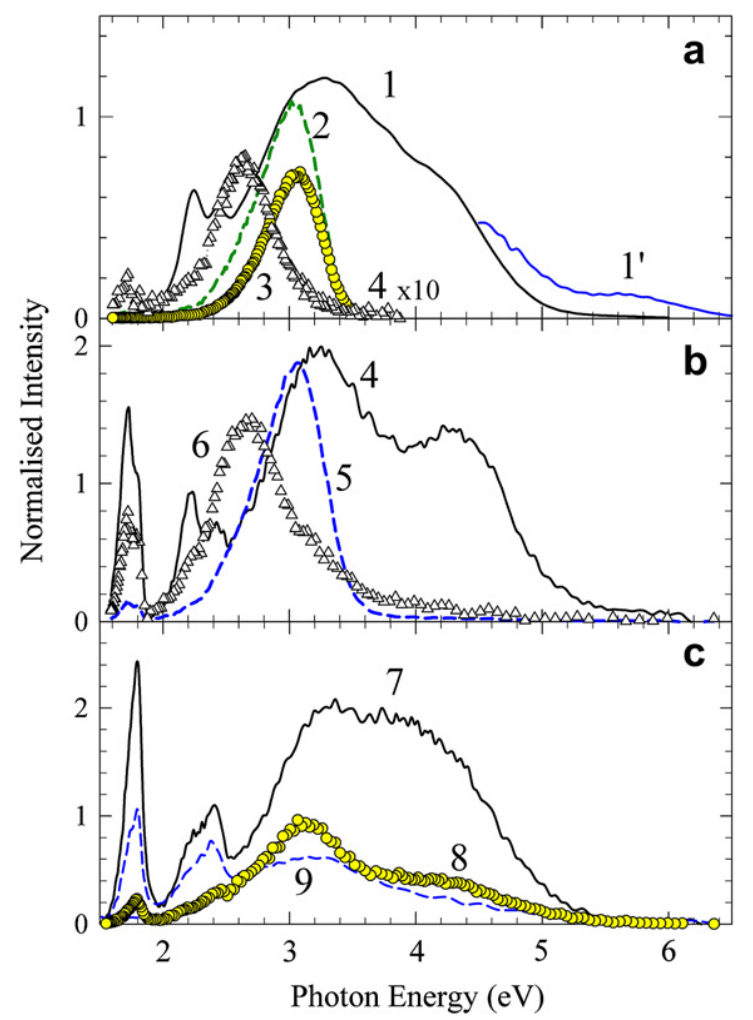

Fig. 1. (a) Cathodoluminescence spectrum (1) of nano-alumina $\left(20 \mathrm{~m}^{2} / \mathrm{g}\right)$ at $5 \mathrm{~K}$ and its VUV-UV part $\left(1^{\prime}\right)$ recorded through a double prism and vacuum monochromator, respectively. The signal intensities of the spectra were adjusted in the overlapping $5.0-5.2 \mathrm{eV}$ region of both monochromators and the curve $\left(1^{\prime}\right)$ is increased by a factor of 5 in order to visualize short-wavelength emissions. Emission spectra of the same sample at $8 \mathrm{~K}$ excited by $4.1 \mathrm{eV}$ photons of TI (2), fast ( $3, \delta t=5.5 \mathrm{~ns}, \Delta t=55 \mathrm{~ns}$ ) and slow components $(4, \delta t=61 \mathrm{~ns}, \Delta t=109 \mathrm{~ns})$. The intensity of latter curve (4) is multiplied by 10. (b) Emission spectra of nano-alumina $\left(20 \mathrm{~m}^{2} / \mathrm{g}\right)$ at $10 \mathrm{~K}$. TI emission excited by $8.27 \mathrm{eV}$ photons (4), TI (5) and slow ( $\delta t=85 \mathrm{~ns}, \Delta t=77 \mathrm{~ns}$ ) component (6) excited by $7.09 \mathrm{eV}$ photons. (c) Emission spectra of nano-alumina $\left(50 \mathrm{~m}^{2} / \mathrm{g}\right)$ at $10 \mathrm{~K}$. TI (7) and fast ( $\delta t=1.8 \mathrm{~ns}, \Delta t=13.9 \mathrm{~ns}$ ) component ( 8 ) excited by $8.27 \mathrm{eV}$ photons and TI emission excited by $16.5 \mathrm{eV}$ photons (9).

Fig. 2 demonstrates high-resolution emission spectra of the $1.7 \mathrm{eV}$ band of both samples at $8 \mathrm{~K}$. The narrow lines starting from $680 \mathrm{~nm}$ are followed by a broad wing extending until $900 \mathrm{~nm}$, which is typical for transition metal impurity emissions. It has been reported in Monteiro et al. (2002) that in this spectral region the ${ }^{4} \mathrm{~T}_{1} \rightarrow{ }^{6} \mathrm{~A}_{1}$ transition of $\mathrm{Fe}^{3+} \mathrm{d}^{5}$ configuration occur in $\alpha-\mathrm{Al}_{2} \mathrm{O}_{3}$, being also identified in nano-structured alumina (Mo et al., 1994). However, $\mathrm{R}_{\Theta}$ doublet (the ${ }^{2} \mathrm{E} \rightarrow{ }^{4} \mathrm{~A}_{2}$ transition of $\mathrm{Cr}^{3+} \mathrm{d}^{3}$ configuration) have been reported at 682.6 and $685.9 \mathrm{~nm}$ (Snytnikov et al., 2008). The positions are practically coinciding with the first two lines in Fig. 2 found at 682.2, 685.7, 688.7 and $691 \mathrm{~nm}$. This indicates the presence of $\mathrm{Cr}^{3+}$ ions substituted to different $\mathrm{Al}^{3+}$ sites or in different phases of nano-alumina. The interaction of octahedrally coordinated $\mathrm{Cr}^{3+}$ ions with $\mathrm{Fe}^{3+}$ impurities leads to the formation of an emission band at $770 \mathrm{~nm}$ (Snytnikov et al., 2008), which partly explains the origin of the long-wavelength wing. The presence of $\mathrm{Ti}^{3+}$ ions with broad-band luminescence at $750 \mathrm{~nm}$ is less probable.

Fig. 3 shows excitation spectra, where the main feature is a notable excitation onset at $\sim 7.5 \mathrm{eV}$ observed for all emissions. It is also in agreement with earlier results (Kirm et al., 2005; Aarik et al., 2005; Gorbunov et al., 2005). This onset is assigned to the beginning of intrinsic absorption of transition alumina. Theoretical studies predict also the reduction of energy gap in a row of $\alpha>\kappa>\Theta>\gamma$ alumina from 6.72 to $4.40 \mathrm{eV}$ (Lee et al., 2007). It is caused by the formation of additional sub-bands on the top of the valence band

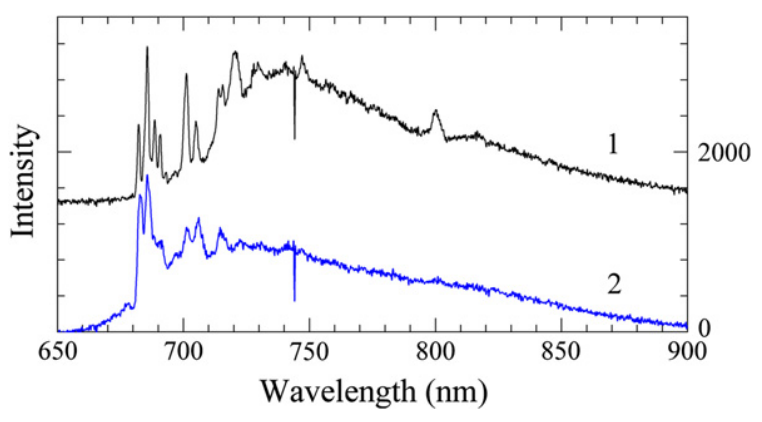

Fig. 2. High-resolution emission spectra of alumina nano-powders ( 20 and $50 \mathrm{~m}^{2} / \mathrm{g} ; 1$, black; 2 , blue lines, respectively) at $8 \mathrm{~K}$ excited by $8.3 \mathrm{eV}$ photons. The spectra were recorded using a CCD camera with the spectral resolution of $1 \mathrm{~nm}$.

due to nonbonding oxygen orbitals in oxides (Mürk, 1997). In transition alumina also a downshift of conduction band bottom occurs caused by change of potentials due to shorter $\mathrm{Al}-\mathrm{O}$ bond distances of $\mathrm{Al}^{3+}$ ions in tetrahedral coordination (Lee et al., 2007).

Two types of self-trapped excitons (STEs) have been revealed in $\alpha-\mathrm{Al}_{2} \mathrm{O}_{3}$ with nanosecond emissions at 7.6 and $3.7 \mathrm{eV}$ (Kirm et al., 1999). The shrinkage of the energy gap by $\sim 1.8 \mathrm{eV}$ of transition alumina also influences the energetic positions of relaxed exited states. UV emission bands are efficiently excited at energies above $7.5 \mathrm{eV}$, which allows us to assign those to intrinsic ones. The $5.5 \mathrm{eV}$ band is due to singlet STE emission with nanosecond decay kinetics (not shown, two decay components $\tau=2.2 \mathrm{~ns}$ and $13.3 \mathrm{~ns}$ ) being an analogue of 7.6 STE emission of $\alpha-\mathrm{Al}_{2} \mathrm{O}_{3}$. The $4.6 \mathrm{eV}$ emission has considerably longer decay time. The $4.3 \mathrm{eV}$ emission with microsecond duration was also observed from nano-ceramics (Kortov

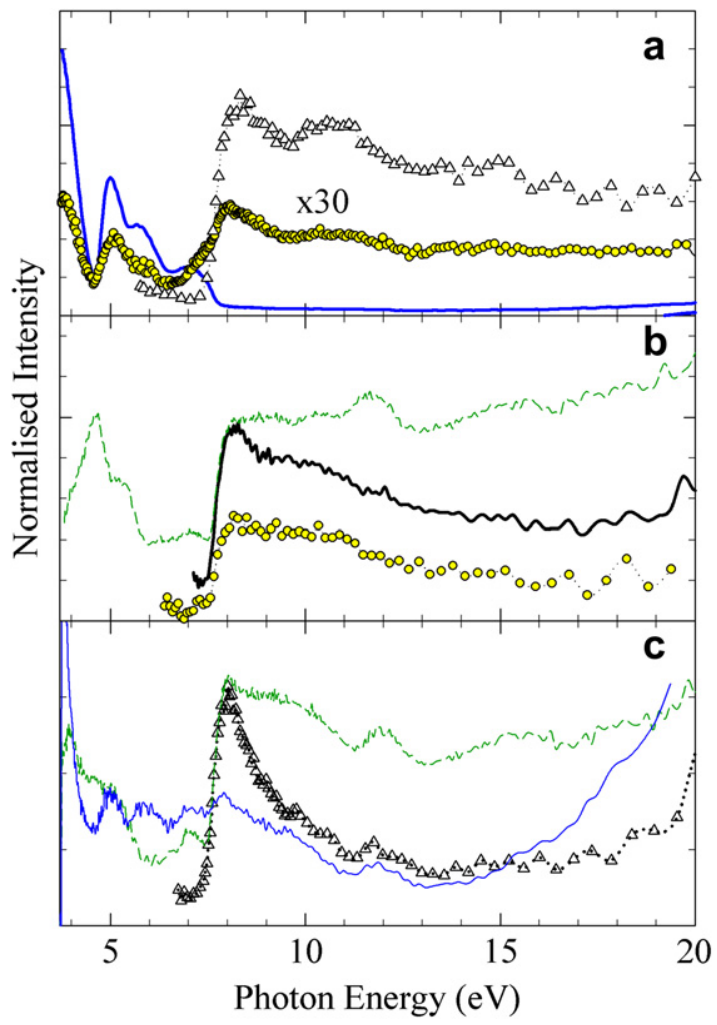

Fig. 3. Excitation spectra of nano-alumina (a,b, $20 \mathrm{~m}^{2} / \mathrm{g} ; \mathrm{c}, 50 \mathrm{~m}^{2} / \mathrm{g}$ ) at $8 \mathrm{~K}$. (a) TI $4.43 \mathrm{eV}$ emission (triangles), TI $3.1 \mathrm{eV}$ emission (solid blue line) and its slow component (circles, $\delta t=61 \mathrm{~ns}, \Delta t=109 \mathrm{~ns}$ ). (b) TI $1.75 \mathrm{eV}$ emission (dashed green line), TI $5.5 \mathrm{eV}$ emission (black line) and its slow component (circles, $\delta t=85 \mathrm{~ns}, \Delta t=77 \mathrm{~ns}$ ). (c) $4.43 \mathrm{eV}$ emission (circles), $3.1 \mathrm{eV}$ emission (solid blue line) and $1.75 \mathrm{eV}$ emission (dashed green line) all recorded in TI mode. 
et al., 2008). Therefore, the $4.6 \mathrm{eV}$ band can be either due to triplet STEs or recombination of electrons and holes near some defect or optically inactive impurity centre.

In the transparency region $(<7.5 \mathrm{eV})$, there is a competition between defect and impurity absorption as the excitation spectra of various centres behave oppositely (Fig. 3a,b). In $\alpha-\mathrm{Al}_{2} \mathrm{O}_{3}$ (Valbis and Itoh, 1991) the presence of $\mathrm{F}^{+}$- and F-centers is well established, emitting at 3.8 and $3.0 \mathrm{eV}$ with decays of $2.1 \mathrm{~ns}$ (Surdo et al., 2001) and $36 \mathrm{~ms}$ (Lee and Crawford, 1979), respectively. The $3.1 \mathrm{eV}$ emission of transition alumina has also a lifetime in the few nanosecond range ( $\tau_{1}=2.7 \mathrm{~ns}$ and $\tau_{2}=12.5 \mathrm{~ns}$ ) and its excitation spectrum consists of 3 peaks, typical for the transparency range of defect rich $\alpha-\mathrm{Al}_{2} \mathrm{O}_{3}$. This $3.1 \mathrm{eV}$ luminescence in our samples originates from $\mathrm{F}^{+}$centers. Earlier the $3.2 \mathrm{eV}$ emission in alumina nanopowders was assigned to the surface $\mathrm{F}^{+}$centers (Gorbunov et al., 2005). The $2.6 \mathrm{eV}$ emission with a long decay is tentatively assigned to F-center luminescence.

Our study did not reveal any significant effects of particle size, which is obviously too large to see any quantum confinement in wide gap insulators with small radius electronic excitations. The main effect observed was the decrease of luminescence intensity because of rising contribution of non-radiative processes on surfaces. The spectral features in the luminescence of $50 \mathrm{~m}^{2} / \mathrm{g}$ alumina samples are influenced by inhomogenous broadening effects.

In conclusion the luminescence properties of mixed $\delta$-, $\Theta-\mathrm{Al}_{2} \mathrm{O}_{3}$ nano-powders were investigated and luminescence bands due to intrinsic excitations, colour centers and transition metal ions identified.

\section{Acknowledgments}

The research has received funding from Estonian Science Foundation (Grant 8306) and from the EC (Grant FP7/2007-2013, grant 226716).

\section{References}

Aarik, J., Kasikov, A., Kirm, M., Lange, S., Uustare, T., Mändar, H., 2005. Optical properties of crystalline $\mathrm{Al}_{2} \mathrm{O}_{3}$ thin films grown by atomic layer deposition. Proc. SPIE 5946, 1-10.

Ching, W.Y., Ouyang, L., Rulis, P., Yao, H., 2008. Ab initio study of the physical properties of $\gamma-\mathrm{Al}_{2} \mathrm{O}_{3}$ : lattice dynamics, bulk properties, electronic structure, bonding, optical properties, and ELNES/XANES spectra. Phys. Rev. B 78014106 $1-13$.

Gorbunov, S.V., Cholakh, S.O., Pustovarov, V.A., Yakovlev, V.Yu., Zatsepin, A.F., Kucharenko, A.I., 2005. Electronic excitations and intrinsic defects in nanostructural $\mathrm{Al}_{2} \mathrm{O}_{3}$. Phys. Stat. Sol. (c) 2, 351-354.

Kirm, M., Zimmerer, G., Feldbach, E., Lushchik, A., Lushchik, Ch, Savikhin, F., 1999. Self-trapping and multiplication of electronic excitations in $\alpha-\mathrm{Al}_{2} \mathrm{O}_{3}$ and $\mathrm{Al}_{2} \mathrm{O}_{3}:$ Sc crystals. Phys. Rev. B 60, 502-510.

Kirm, M., Lushchik, A., Ch, Lushchik, 2005. Creation of spatially correlated excitations and defects in wide-gap solids. Phys. Stat. Sol. (a) 202, 213-220.

Kortov, V.S., Ermakov, A.E., Zatsepin, A.F., Uimin, M.A., Nikiforov, S.V., Mysik, A.A., Gaviko, V.S., 2008. Specific features of luminescence properties of nanostructured aluminum oxide. Phys. Sol. State 50, 957-961.

Lee, K.H., Crawford Jr., J.H., 1979. Luminescence of F center in sapphire. Phys. Rev. B 19, 3217-3221.

Lee, C.-K., Cho, E., Lee, H.-S., Seol, K.S., Han, S., 2007. Comparative study of electronic structures and dielectric properties of alumina polymorphs by first-principles methods. Phys. Rev. B 76 (245110), 1-7.

Monteiro, T., Boemare, C., Soares, M.J., Alves, E., Marques, C., McHargue, C., Ononye, L.C., Allard, L.F., 2002. Luminescence and structural studies of iron implanted $\alpha-\mathrm{Al}_{2} \mathrm{O}_{3}$. Nucl. Instrum. Methods B 191, 638-643.

Mo, C.-H., Zhang, L., Yao, X., Fan, X., 1994. Fluorescence associated with $\mathrm{Fe}^{3+}$ ions in nanostructured $\mathrm{Al}_{2} \mathrm{O}_{3}$. J. Appl. Phys. 76, 5453-5456.

Mürk, V., 1997. Exciton relaxation in wide-gap complex oxides. Materials Science Forum 239, 537-542.

Palcevskis, E., Reichel, U., Lipe, A., 2001. Sintering of nanosized plasma-processed $\mathrm{Al}_{2} \mathrm{O}_{3}$ powders. Proceedings of Xth International Baltic Conference "Materials Engineering \& Balttrib 2001", Riga, Latvia, pp. 87-91.

Snytnikov, V.N., Stoyanovskii, V.O., Larina, T.V., Krivoruchko, O.P., Ushakov, V.A. Parmon, V.N., 2008. Laser-induced luminescence of model $\mathrm{Fe} / \mathrm{Al}_{2} \mathrm{O}_{3}$ and $\mathrm{Fe} /$ $\mathrm{Al}_{2} \mathrm{O}_{3}$ catalysts. Kinetics Catal 49, 291-298.

Surdo, A.I., Kortov, V.S., Pustovarov, V.A., 2001. Luminescence of $\mathrm{F}_{\text {and }} \mathrm{F}^{+}$centers in corundum upon excitation in the interval 4 to $40 \mathrm{eV}$. Radiat. Meas 33,587-591.

Valbis, J., Itoh, N., 1991. Electronic excitations, luminescence and lattice defect formation in $\alpha-\mathrm{Al}_{2} \mathrm{O}_{3}$ crystals. Rad. Effects Defects Solids 116, 171-189.

Zimmerer, G., 2007. SUPERLUMI: a unique setup for luminescence spectroscopy with synchrotron radiation. Radiat. Meas 42, 859-864. 